\title{
Upgrade of the cryogenic systems of Wendelstein $7-\mathrm{X}$
}

\author{
Thomas Rummel, Michael Nagel, Michael Pietsch, Sylvio Raatz, C. P. Dhard, Andreas Braatz, Marko \\ Ihrke, Hans-Stephan Bosch, and the W7-X team
}

\begin{abstract}
The Wendelstein 7-X experimental device has completed the third plasma operation campaign in November 2018. The running, two year shut down phase is being used to install new diagnostics, new in-vessel-components (steady-state divertor and cryo pumps) and their auxiliary supply systems. Especially the installation of the ten cryo pumps requires a substantial upgrade of the cryo systems. The work package comprises the installation of a 55 meters long new transfer line from the cryo plant to the new valve box and the installation of ten transfer lines with lengths up to 15 meters from the valve box to the ten cryo vacuum pumps in the plasma vessel. The tasks has been split into two main contracts in industry. Both contracts are presently running, the production of the transfer lines and the valve box per September 2019 is in an advanced status. The aim is to complete the production in early 2020 and the installation work end of 2020. A second task regarding the cryo systems is the upgrade with respect to the foreseen long pulse operation of W7$X$. Therefore, new storage tanks for helium gas and for liquid nitrogen are necessary. The helium gas storage has been installed end of 2018 whereas the liquid nitrogen storage tank is presently under design. The paper gives an overview about individual upgrade tasks of the W7-X cryo systems, highlights the special design requirements and reports the status of the contracts.
\end{abstract}

Index Terms-Cryogenic systems, nuclear fusion devices, transfer lines.

\section{INTRODUCTION}

$\mathrm{T}$ HE Wendelstein 7-X experimental fusion device has completed the third plasma operation campaign in November 2018 with outstanding results, especially in terms long pulse operation of up to $100 \mathrm{~s}$ and divertor operation [1][4]. The running, two-year shut down phase is being used to install new in-vessel-components (steady-state divertor and cryo pumps), the corresponding water cooling circuits and other auxiliary supply systems and new diagnostics.

Especially the operation of ten cryo pumps will increase the pumping power behind the divertors, and thus support the

This paragraph of the first footnote will contain the date on which you submitted your paper for review.

This work has been carried out within the framework of the EUROfusion Consortium and has received funding from the Euratom research and training programme 2014-2018 and 2019-2020 under grant agreement number 633053. The views and opinions expressed herein do not necessarily reflect those of the European Commission.

All authors are with the Max-Planck-Institute for Plasma Physics, D-17491 Greifswald, Germany (corresponding author's e-mail: thomas.rummel@ipp.mpg.de). steady-state plasma operation. Details about the W7-X cryo vacuum pumps can be found in [5].

Consequently, the cryogenic system has to be upgraded to supply the new components. These measures are described in chapter III.

Another motivation for an upgrade is an important lesson from the first three operation phases: the amount of helium gas that comes back from the superconducting magnets after a fast discharge of the magnet system is much higher than assumed in the design of the cryo plant. This leads to a partial overload of the internal heat exchanger. Countermeasures to overcome this systematic issue are described in chapter IV.

\section{OVERVIEW ABOUT THE CRYOGENIC SYSTEM OF W7-X}

The cryogenic system of W7-X consists mainly of the helium refrigerator, storage tanks for helium and nitrogen and the consumers of the cold media. The refrigerator has an equivalent cooling power of $7 \mathrm{~kW}$ at 4.5 Kelvin, which requires an electrical power of about 1.6 MW. Main components are the compressor unit, which contains two screw compressors, and an oil removal system and a dryer connected in series. A cold box with seven turbine expanders, two cold compressors and a sub cooler box with four cold circulators are other main components. A main transfer line to a magnet valve box serves as the interface to the W7-X machine. There are four storage tanks for helium gas with 250 cubic meters each, one liquid helium tank with a volume of 10000 liters and one liquid nitrogen storage tank of 30000 liters. A detailed description of the system can be found in [6].

The main purpose so far was to supply the main cryogenic components of W7-X like superconducting coils and bus bars, the cold mechanical support structure, and the low temperature parts of the superconducting current leads (all with helium at around 4 Kelvin). The thermal shield of the cryostat, which consists mainly of the shield of the outer vessel, the shield of the plasma vessel and the shields of the 254 ports are supplied with helium gas at about $50-70 \mathrm{~K}$ in addition. Finally, the high-temperature-superconducting part of the current leads are supplied with helium gas at $50 \mathrm{~K}$. 


\section{UPGRADES TO SUPPLY NEW COMPONENTS}

\section{A. Motivation}

Each of the ten new cryo vacuum pumps (CVP) needs to be supplied with liquid helium and liquid nitrogen. Therefore a new CVP main transfer line from the existing cryo plant to a new cryo valve box (CVB) and ten new transfer lines from the CVB to the cryo pumps have to be designed, produced and installed. In addition, a new liquid nitrogen storage tank is necessary. The nitrogen consumption due to the operation of the cryo pumps would otherwise require the delivery of liquid nitrogen every other day. Fig. 1 shows the main components of the cryo supply for the cryo vacuum pumps in relation to the W7-X cryostat and the inner support tower.

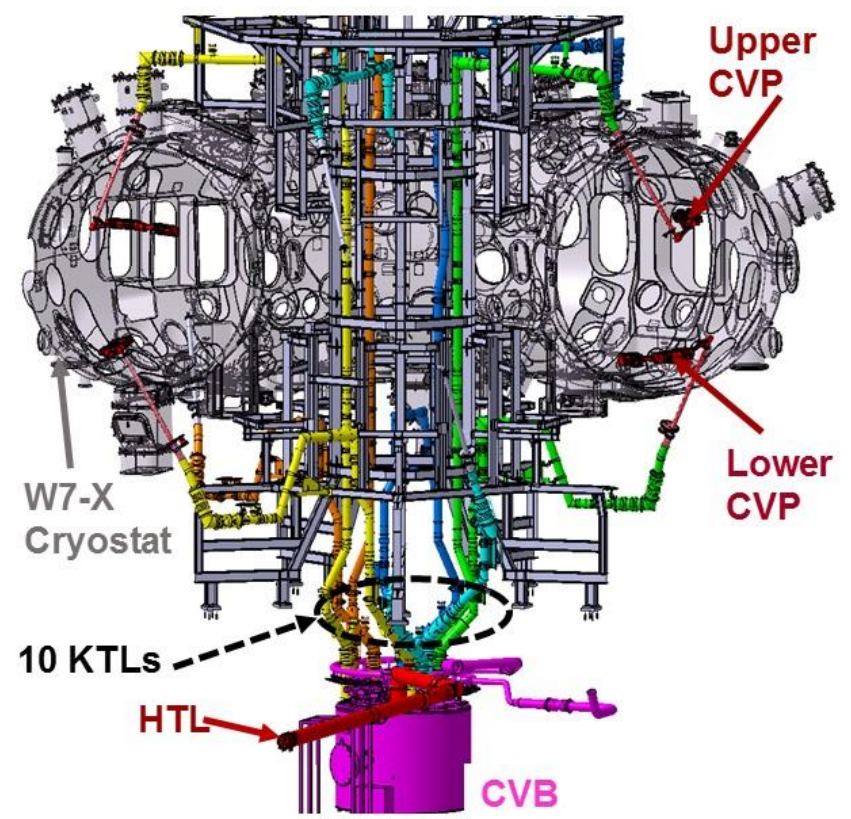

Fig. 1. Main components of the cryo supply of the cryo vacuum pumps in W7-X (CVP: cryo vacuum pump; CVB: cryo pump valve box; KTL: individual transfer line from the CVB to the cryo pumps; HTL: main transfer line from the sub-cooler box to the CVB).

\section{B. New CVP main transfer line}

The CVP main transfer line is a multi channel transfer line containing two process pipes for helium and two process pipes for nitrogen. The outer diameter of the vacuum jacket is 273 $\mathrm{mm}$, whereas the process pipes have a diameter of $48 \mathrm{~mm}$ each. All pipes are made of stainless steel 1.4571, as requested by the general design requirements of $\mathrm{W} 7-\mathrm{X}$ for helium pipes near the cryostat. The proper distance and a good thermal separation between the process pipes will be secured with supports made of glass fiber reinforced plastic (GRP). For better thermal insulation, the helium pipes are wrapped with superinsulation. The nitrogen return line is connected by brazing to a thermal shield made of copper. The vacuum of the transfer line is separated from the vacuum of the sub cooler box of the refrigerator and from the vacuum of the new valve box. The total length of the transfer line will be 55 meters. To allow the assembly under the very tight space conditions the transfer line consists of 13 individual segments with maximum length of 4.6 meters and a maximum weight of $350 \mathrm{~kg}$ each.

\section{New valve box for the CVP}

The cryo vacuum pump valve box (CVB) is located in the second basement underneath the W7-X, close to the existing valve box for the magnet system. The main purpose of the CVB is to distribute the helium as well as the nitrogen flow coming via the CVP main transfer line to the ten cryo pumps via the individual CVP transfer lines. In addition, the cold valves, temperature sensors, mass flow sensors and pressure sensors are part of the box. To handle different heat loads on the cryo pumps each individual feed process line can be controlled by a separate valve. The return flows are collected in two headers, one for helium and one for nitrogen. The helium return flow will go back to the refrigerator. The nitrogen return flow will be partly used for pre-cooling of helium inside the refrigerator and then released into the air outside the building.

The CVB will have an outer diameter of 2.5 meters and a height of about 2 meters (without auxiliary components). The expected mass is in the order of 5 tons. Like most of the other components of the cryo pump supply system the box is made of stainless steel. The CVB contains also the safety valves for all process pipes of the transfer lines, the CVP main transfer line as well as of the ten individual CVP lines. Fig. 2 shows the CAD model of the CVB.

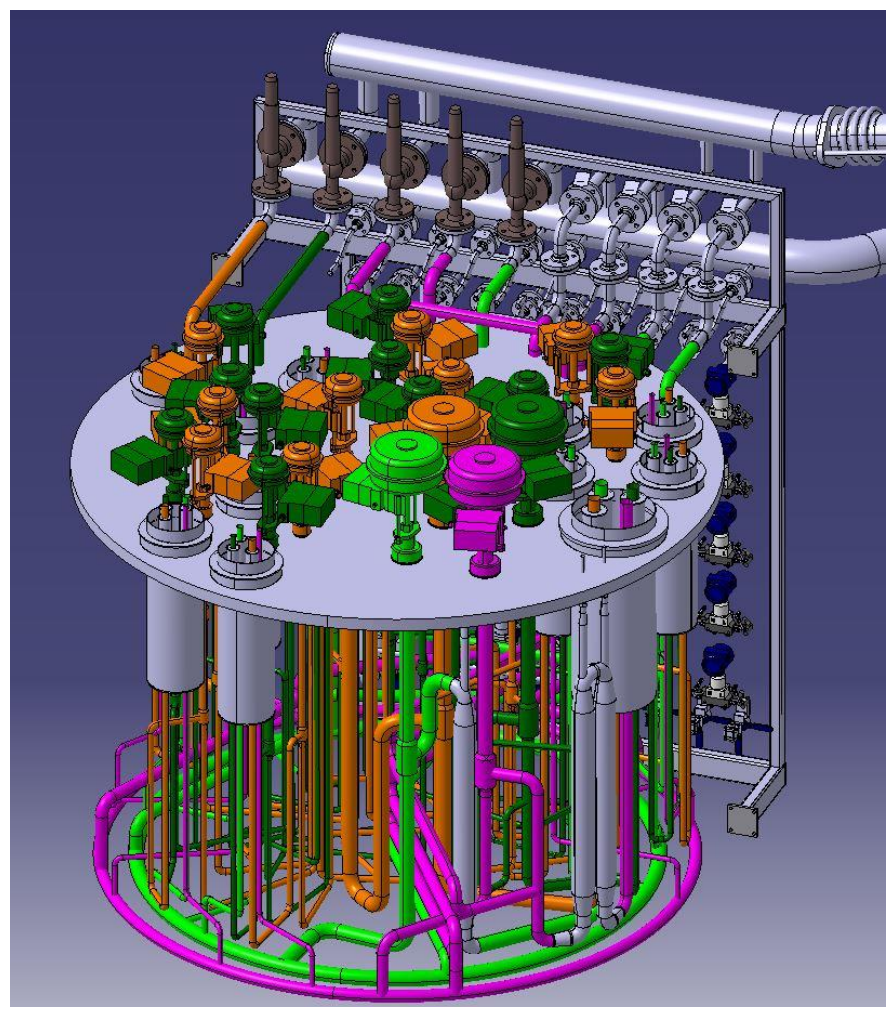

Fig. 2. CAD model of the CVB (shown without housing) with the valve rack in the back and the collector lines for the nitrogen and helium return flows. 
As usual, the CVB design gives the possibility to establish a short circuit between the feed and return line of the main CVP transfer line, and closing the valves to the cryo pumps at the same time. This will lead to a decoupling of the W7-X from the supply system without stopping the mass flows from the refrigerator. Especially during the commissioning and for tests and adjustments this function will be useful. The CVB contains also electrical heaters in the process pipes $(1 \mathrm{~kW}$ in the helium line and $8 \mathrm{~kW}$ in the nitrogen line) to simulate the heat load on the cryo pumps and their individual transfer lines. The valve box control, the processing of the sensor signals and the data collection will be performed by a local PLC (Programmable Logic Controller), which will be installed in a rack close to the CVB.

Another rack associated to the CVB will host the vacuum pumping unit for the CVB and for all transfer lines.

The CVB is handled as a separate project that means the procurement is being done independently from the procurement of the transfer lines. It reduces the workload to a single supplier and allows a parallel execution of the orders for transfer lines and CVB. On the other hand, the effort for coordination and a detailed interface description is higher on the side of the contractor.

The CVB is being designed and built in industry by the company Cryoworld in Wieringerwerf, Netherlands. The contract was placed in June 2018. In July 2019 the status is as follows: the final design of the CVB was approved in May 2019, the design of the external piping is running, the fabrication of the box is expected to start in August 2019, and will be ready for shipment in autumn 2019. The installation in W7-X will be completed in first half of 2020, when all transfer lines will be in place.

\section{New transfer lines from the valve box to the cryo pumps}

The ten transfer lines to the cryo pumps are running from the CVB to a dedicated port at the outside of the cryostat. The ports serve as the interface to the in-vessel-pipes which serve finally the cryo pumps. The cryo pumps in $\mathrm{W} 7-\mathrm{X}$ are placed symmetrically around the circumference of the plasma vessel and symmetrically to the horizontal plane of the plasma vessel as well. That means five cryo pumps are located in the upper part of the vessel, and five cryo pumps are located in the lower part of the vessel. Therefore, the transfer lines are divided into transfer lines for the upper cryo pumps and transfer lines for the lower cryo pumps. The basic concept was that all the five upper and all the five lower transfer lines should have the same routing. Unfortunately the installations outside of the W7-X basic machine like cable trays, water pipes, support structures and of course diagnostics are not symmetrically anymore. The originally reserved space for the transfer lines are meanwhile used by other components. The main consequence was that the routing of each transfer line had to be adapted to the individual space restrictions of a specific transfer line. The transfer lines now have individual routings and several direction changes were necessary compared to the original design. All these new conditions had a considerable influence to the necessary design resources and to the time needed to find an acceptable technical solution. In general, it is one of the drawbacks of the strategy for a stepwise completion of a complex system. From the technical point of view, the design had to be made from the outside to the inner side instead of the usual way from the inner side (process requirements) to the outer side. That means at first the maximum available outer diameter was the outer limit of the outer vacuum pipe of a transfer line. The process pipes with the supports and the thermal shield and the thermal insulation had than to be designed accordingly. That led to relatively small process pipe diameters, higher pressure drop and higher thermal losses. The final lengths vary between 12 meters and 16 meters. Nevertheless, it could be managed to keep some standardization in the design. All transfer lines have an outer diameter of $159 \mathrm{~mm}$ on its straight parts, at locations with direction changes the diameter is $219 \mathrm{~mm}$. The process pipes have an outer diameter of $21.3 \mathrm{~mm}$ and a wall thickness of 2 $\mathrm{mm}$. The helium lines are wrapped with 10 layers of superinsulation each. The return line of the nitrogen pipe is connected to the thermal shield tube, made of $2 \mathrm{~mm}$ thick copper and $105 \mathrm{~mm}$ diameter. In addition, the thermal shield is wrapped with superinsulation. Fig. 3 shows a picture of a production sample.

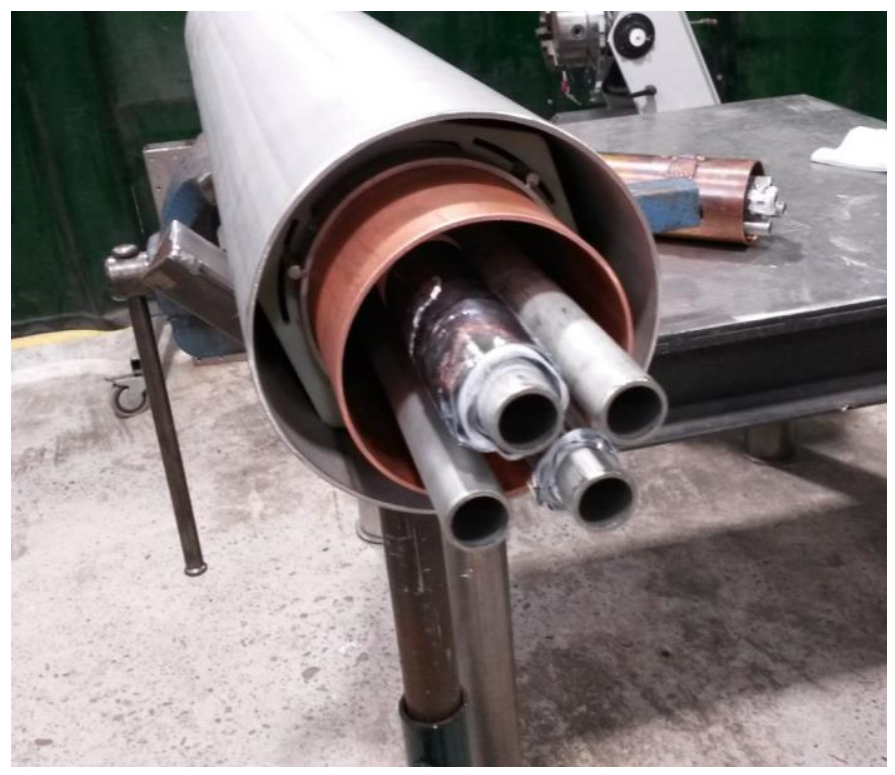

Fig. 3. Production sample of a transfer line running from the CVB to the cryo pump. Helium lines (top left and lower right tubes) are wrapped with superinsulation.

Each transfer line has its own vacuum. There are vacuum barriers to the CVB and to the cryo pump ports of the W7-X machine. The vacuum shell is equipped with safety valves to avoid overpressure in failure conditions like the break of a process pipe.

The final design of the transfer lines, the main transfer line (chapter III B) as well the ten small transfer lines to the cryo 
pumps was made together with industry in a one year contract. The fabrication of the transfer lines was awarded in April 2017 to the same company, Cryotherm from Kirchen, Germany, and is presently running. By July 2019 nine of the ten short transfer lines have been fabricated. Eight of them are already installed in W7-X. The design of the main transfer line is finished, the production will start in August 2019 and all segments are planned to be delivered to the W7-X site by end of 2019. The installation sequence of all the described components is as follows: Due to the space constraints the transfer lines to the cryo pumps will be installed first, than the main transfer line will be installed. The installation of the transfer lines requires the welding of the segments on-site. First, the welding of the four process pipes, then the application of the superinsulation and finally closing of the vacuum jacket by welding. Afterwards the CVB will be brought at its final place. The last step will be the connection of all transfer lines to the CVB. The auxiliary components will be installed afterwards, the vacuum pump for the 12 vacuum zones, the rack with the sensor electronics and the local control system. The completion of all the tasks is planned for mid of 2020 .

\section{E. New liquid nitrogen storage tank}

Up to now the cryo plant was operated without any usage of liquid nitrogen for supporting the refrigeration process. When the cryo pumps have been integrated in the system a different operation regime will be used.

The helium refrigerator has to take an additional load of $450 \mathrm{~W}$ at $4 \mathrm{~K}$ when the CVP are in operation. Therefore, the cooling power of the cryo plant will be increased by using 377 1/h (steady-state) of LN2 for pre-cooling. The heat load on the shield of the CVP requires $93 \mathrm{l} / \mathrm{h}$ LN2 in standby condition. Stand-by condition means the whole day except the duration of the plasma shots. During plasma operation with ECRH heating the expected heat load of up to $12 \mathrm{~kW}$ to the CVP requires up to $320 \mathrm{l} / \mathrm{h}$ of LN2. Assuming a daily plasma operation of 3 hours, the total liquid nitrogen consumption will be 11960 liters per day.

The existing liquid nitrogen tank has a nominal volume of 30,000 liters, but due to safety restrictions and the need of keeping always a minimum level in the tank the usable volume is about 20,000 liters only. Taking into account the expected consumption as stated above, it is clearly visible that a 3-days-per-week operation regime as it is planned for the next campaigns of $\mathrm{W} 7-\mathrm{X}$ requires at least one refilling during the operation week. In case of a skipped or even delayed delivery of LN2, the operation week would have to be stopped or interrupted. To overcome this potential risk, it was decided to install a second LN2 storage tank.

The new tank will be a copy of the existing tank. It is a double wall tank, the inner vessel is the product vessel and the outer vessel serves as the cryostat. The new tank will have a usable volume of 30 cubic meters. The maximum allowed pressure is 19 bars, but the operating pressure is adjustable between 2 and 10 bars. As the new tank will be used only for an extension of the delivery duration and not to an increase of the delivered mass flow rate, the existing transfer line with a nominal diameter of $40 \mathrm{~mm}$ from the tank to the cold box of the helium refrigerator will not be doubled.

By July 2019, the basic design requirements have been defined. The drafting of the technical specification is going to start in autumn this year.

\section{UPGRADES BASED ON OPERATION EXPERIENCES}

\section{A. Motivation}

During commissioning and operation of the W7-X several fast discharges of the superconducting magnet system were conducted, planned as well as unplanned. Test of safety systems as well as general failures like loss of the grid voltage normally lead to a trip of the refrigerator's connection to the W7-X by closing the valves. One experience was that in all cases were the cryo plant was disconnected from the W7-X and the screw compressors tripped the restart procedure created problems with the handling of the cold helium gas. To improve the gas handling, an additional heat exchanger is being designed. A second measure to improve the handling of the helium gas is the procurement of an additional helium gas storage tank.

\section{B. Additional heat exchanger for cold helium gas}

The cryo plant will be automatically disconnected from W7-X cryostat in case of a trip of the cryo plant caused by instable operation regimes, signal failures or utility failures. The quench of the superconducting magnets or a fast discharge can also lead to a trip of the cryo plant. A full reconnection of the cryo plant with the W7-X cryostat after the reason for the trip has been clarified, requires that the process pipes together with the helium volumes must be depressurized inside the W7-X cryostat first.

The helium amount inside the cryostat is about $470 \mathrm{~kg}$. Depressurizing requires that a big fraction of that cold helium (liquid/gas) have to be warmed up to room temperature and returned to the gas storage within a few hours.

Kilograms of gas or liquid helium will flow back from the W7-X cryostat through the heat exchangers of the cold box. The mass flow cannot warm up inside the counter flow heat exchangers because there is not any relevant warm counter flow to balance the heat exchange. So cold gas leaves the cold box and enters the suction side of the warm compressor. Finally, the compressor unit pushes the outlet gas to the warm storage tanks.

The cold gas cools down the carbon steel end cap of the cold box and the temperature might drop below the lower acceptable limit for that carbon steel (about 223K). This might lead to embrittlement. Humidity will freeze on the cold 
connection pipes. The lubrication oil inside the compressors might cool down below the allowed limits and might even freeze. Therefore, it is planned to install a parallel flow path that comes into action when the cold box is disconnected. This flow path allows heating of the return flow to ambient temperature with the help of a conventional fin tube heat exchanger located outside the building and taking the required heat from the environment.

The new heat exchanger will consist of two units of a power of $50 \mathrm{~kW}$ each. The layout will be similar to the one existing heat exchanger using external fin tubes in vertical orientation made of aluminum. The design inlet temperature is $40 \mathrm{~K}$ at a mass flow of $70 \mathrm{~g} / \mathrm{s}$. The whole system will be installed outside of the cryo building.

By July 2019, the preliminary design has been finished and the technical specification was drafted.

\section{Additional warm helium gas tank}

The present concept of the gas storage system foresees a storage volume of $4 \times 250$ cubic meters for helium gas at max. 19 bar. This concept secures that in case of warming up to room temperature the total helium inventory of the $\mathrm{W} 7-\mathrm{X}$ as well as of the helium refrigerator plant is possible to store in gas tanks. The remaining pressure in the systems is than in the uncritical range of 2-3 bar. But in case a significant amount of helium is lost during operation caused by blow off of safety valves or even a breakage of rupture discs no spare helium would be available to continue with the operation. Further helium leakages and purging procedures after maintenance activities also leads to loss of helium. At the time of the design in the mid-90s of the last century, this was no issue, but meanwhile the price for helium has increased drastically and there is a shortage of helium on the market. Therefore, it was decided to buy one additional helium gas storage tank with a volume of 250 cubic meters. This will enlarge the total storage volume by $25 \%$. The total storage volume of the five tanks is now large enough to store the total amount of helium gas of the W7-X cryo systems. This avoids the loss of helium during opening of the cryo plant and/or the W7-X cryo line distribution system.

Also in case of a quench the storage volume will be large enough to have always one tank available for taking over the gas after a quench. In general the sequence in case of a quench is as follows: Before the experiment starts, it is ensured that the dedicated quench gas tank has a pressure of 1.3 to 1.5 bar. In case of a quench the safety valves open at a pressure of 17 bar and helium can flow into the quench tank. Later the warm screw compressors are used to empty the quench tank again and pump the gas into the other storage tanks sitting at higher pressure.

The design of the new tank was tried to make as similar as possible with respect to the existing tanks. Unfortunately, the company, which designed and delivered the first four tanks in the year 2000, does not exist anymore. Therefore, the design of the fifths tank slightly deviates from the design of the first four tanks, but the main parameters are similar. As the first four tanks, the new tank has a volume of 250 cubic meters, is made of carbon steel (material number 1.0566), and has a length of 22 meters and an outer diameter of 4 meters. The maximum operation pressure is 18 bar, safety valves are installed to avoid dangerous overpressure.

The enlarged storage volume offers the change to use the new tank as a dedicated quench gas tank. That makes it possible to customize the interface to the quench gas line accordingly. In case of a quench the helium gas coming from the magnets can contain a certain amount of liquid helium as well. To avoid that liquid helium drops onto the bottom of the carbon steel tank with the risk of overstressing the material (the minimum allowed temperature is $-60^{\circ} \mathrm{C}$ for the used carbon steel), the helium inlet is equipped with an internal diffusor. The diffusor is an 18 meters long pipe of $170 \mathrm{~mm}$ diameter in the inner volume of the tank and has 720 small holes (every $200 \mathrm{~mm} 8$ holes around the circumference) with a diameter of $7 \mathrm{~mm}$. The helium is sprayed through these small holes into the tank and mixes with the warm helium in the tank. This warms it up and distributes it more uniformly in the volume.

The tank was designed, build tested delivered in industry, by the company A. Silva-Matos from Aveiro, Portugal. The contract was placed in October 2017, the design was finished in December 2017, the fabrication ran in 2018 and the tank arrived at its final place next to the existing tanks in December 2018. The pipe, which connects the new tank with the other tanks and with the quench gas line from the $\mathrm{W} 7-\mathrm{X}$ is under design. The integration into the existing system will be finished in 2021.

\section{SUMMARY}

The cryogenic systems of Wendelstein $7-\mathrm{X}$ were successfully operated during the first three experimental campaigns in 2015, 2016 and 2018. During the completion phase of W7-X a major upgrade is running. There are two main motivations for the upgrade. The first set of measures are necessary to supply the new components in the plasma vessel, the ten cryo vacuum pumps, with helium and nitrogen. The second set of measures is based on operation experiences and will also support the robustness of the cryo systems during the upcoming experimental campaigns. The upgrade activities, are running internally and in industry and progressing well.

\section{ACKNOWLEDGMENT}

The authors thank all the involved colleagues in IPP as well as the various industrial partners for the valuable contributions. 


\section{REFERENCES}

[1] H.-S. Bosch et al., "Final integration, commissioning and start of the Wendelstein 7-X stellarator operation," Nucl. Fusion, vol. 57, no. 11, p. 116015, 2017.

[2] T.S. Pedersen et al., "First results from divertor operation in Wendelstein 7-X," Plasma Physics Contr. Fusion, vol. 61, p.014035, 2019.

[3] R. Wolf et al., "Major results from the first plasma campaigns of the Wendelstein 7-X stellarator," Nucl. Fusion, vol. 57, no. 11, p. 102020, 2017.

[4] M. Hirsch at el., "Major results from the stellarator Wendelstein 7-X," Plasma Phys. Control. Fusion 50, 053001 (2018). doi:/10.1088/0741-3335/50/5/053001

[5] G. Ehrke et al., "Design and manufacturing of the Wendelstein 7-X cryo-vacuum pump," Fusion Eng. and Design, Volume 146, Part B, September 2019, pp. 27572760.

[6] C. P. Dhard, M. Nagel, S. Raatz, U. Nuesslein, and M. Ressel, "Final acceptance tests of helium refrigerator for Wendelstein 7-X," Physics Procedia, vol. 67, pp. 83-88, 2015.

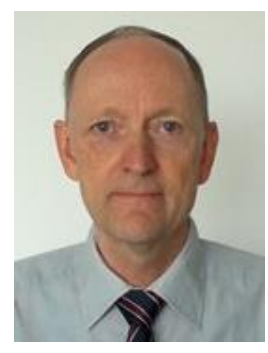

Thomas Rummel has studied Electrical Engineering and received the Dipl.-Ing. and the Dr.-Ing. degrees from the University of Magdeburg, Germany, in 1989 and 1996, respectively. He joined the Max-Planck-Institute for Plasma Physics (IPP) Garching in 1998 and has been working for Wendelstein $7-\mathrm{X}$ in the IPP Greifswald in the fields of superconducting magnets, magnet protection and magnet power supplies since then. In 2001, he became the head of the magnet and power supply department. Since 2015 he is the head of the magnet and cryogenics division of Wendelstein 7-X.

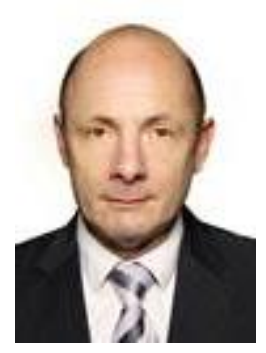

Michael Nagel received the Dipl.-Ing. and Dr.-Ing degrees in Chemical Engineering from the Technical University of Karlsruhe, Germany in 1990, and from the University of Karlsruhe in 1995, respectively.

$\mathrm{He}$ joined the Max-Planck-Institute for Plasma Physics, Greifswald, Germany in 1999. He has been involved in cryogenics for Wendelstein 7-X Project. He is leader of the cryogenic team. His working field covers thermodynamics, fluid dynamics and their applications in cryogenics.

Michael Pietsch, photograph and biography not available at the time of publication.

Sylvio Raatz, photograph and biography not available at the time of publication.

C. P. Dhard, photograph and biography not available at the time of publication.
Andreas Braatz, photograph and biography not available at the time of publication.

Marko Ihrke, photograph and biography not available at the time of publication.

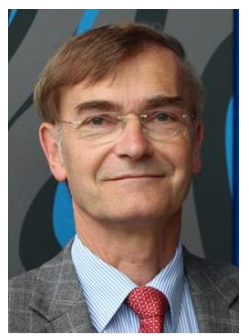

Hans-Stephan Bosch has studied physics in Münster and Munich. He received the Dr. rer. nat. degree from the Technical University, Munich, in 1986, and the Habilitation degree from Humboldt University, Berlin, Germany, in 2000. In August 2016 he was appointed as a professor at TU Berlin.

After his post-doc- time at TFTR in Princeton, he worked on ASDEX and ASDEX Upgrade at IPP, Garching. In 2000 he changed the field, becoming head of the Director's Office. In 2004 he joined the project Wendelstein 7-X as head of Project Coordination. Since 2013 he is the "Director Operations" for Wendelstein 7-X and deputy head of W7-X of the Max-Planck-Institute for Plasma Physics. 